\title{
EL ARTE COMO EPOCHÉ Y REDUCCIÓN EIDÉTICA. LA FUNDAMENTACIÓN DE LA ESTÉTICA DE ORTEGA Y GASSET EN LA FENOMENOLOGÍA HUSSERLIANA
}

\author{
ANTONIO GUTIÉRREZ POZO \\ Universidad de Sevilla
}

\begin{abstract}
RESUMEN: Este artículo muestra cómo la estética de Ortega y Gasset es una estética fenomenológica porque se fundamenta sobre la fenomenología de Husserl. La comprensión orteguiana del arte como epoché y reducción eidética es una prueba de ello. La deshumanización o desrealización del arte, concepto central de la estética de Ortega, consiste en realizar la epoché y la reducción eidética hacia la pura conciencia o conciencia de. Según Ortega, el arte siempre ha sido epoché y reducción espontáneas. El arte de vanguardia las practica de forma consciente.
\end{abstract}

PALABRAS CLAVE: Ortega y Gasset; arte; fenomenología; deshumanización; epoché; reducción eidética.

\section{Art as epoché and eidetic reduction. The foundation of Ortega y Gasset's aesthetics on Husserl's phenomenology}

ABSTRACT: This paper shows how Ortega y Gasset's aesthetics is a phenomenological aesthetics as it is based on Husserl's phenomenology. The Orteguian understanding of art as epoché and eidetic reduction serves as evidence for this. The dehumanization or derealization of art, a central concept of Ortega's aesthetics, consists of carrying out both epoché and eidetic reduction towards the pure conciousness or conciousness of. According to Ortega, art has always been epoché and spontaneous reduction. Avant-garde art represents the conscious practice of them.

KEY WORDS: Ortega y Gasset; art; phenomenology; dehumanization; epoché; eidetic reduction.

\section{INTRODUCCIÓN. EstÉticA FENOMENOLÓGICA Y DESHUMANIZACIÓN}

\subsection{Deshumanizar y desrealizar}

La primera precisión que hay que hacer cuando nos acercamos a la estética de Ortega entendida como reflexión o disciplina filosófica es que resulta evidente que para él es sinónimo de filosofía del arte. Prueba de ello es la identificación implícita que subyace a lo largo de todo el Ensayo de estética a manera de prólogo de 1914 entre obra de arte y objeto estético, y que se muestra casi explícitamente cuando afirma que «el objeto estético es una intimidad en cuanto tal - es todo en cuanto yo", para inmediatamente advertir que esto no quiere decir que «la obra de arte nos descubra el secreto de la vida y del ser»${ }^{\text {. Todavía más }}$ evidente es la asimilación de estética y filosofía del arte en Adán en el paraíso de 1910 cuando escribe que si «los aficionados al arte suelen sentir desvío por la

1 Ortega y Gasset, J., Ensayo de estética a manera de prólogo (1914) (en adelante: EEP, insertado en el texto, salvo si se cita en nota), Obras Completas, v. I, Madrid, Fundación Ortega y Gasset/Taurus, 2007, p. 672. 
estética», ello se debe a que «la estética pretenden encajar en la cuadrícula de los conceptos la plétora inagotable de la sustancia artística» ${ }^{2}$, es decir, al hecho de que consiste en filosofía del arte que pretende captar la presencia emocionante de la belleza artística en la precisión rigurosa del concepto. Cuando poco después Ortega asegura que «la estética vale tanto como el arte» ${ }^{3}$, además de insistir en la equivalencia entre estética y filosofía del arte, añade que una buena estética no debe pensar conceptualmente la belleza artística para ponerse en su lugar, como temían los aficionados del arte, sino para servirle de auxiliar que permita incrementar la propia experiencia de la belleza mediante la lucidez del concepto. En este trabajo pretendemos mostrar en qué sentido la estética de Ortega y Gasset —su filosofía del arte por tanto- es una estética fenomenológica $^{4}$. La tesis que vamos a desarrollar en este escrito es que la filosofía del arte de Ortega es fenomenológica en el sentido de que se fundamenta sobre la fenomenología de Husserl, algo que resulta ya evidente en el Ensayo de estética de 1914 escrito justamente tras la lectura temprana de Ideen I, texto cuya primera recepción inmediata por parte de Ortega se materializó en Sobre el concepto de sensación de 1913. Ciertamente no hay una estética o filosofía del arte husserliana en el sentido más habitual del término y mucho menos en 1914, que es la fecha en la que nos encontramos ya por primera vez con esta base fenomenológico/husserliana en la estética de Ortega. Husserl no consagró ninguna obra ni ninguna lección completa a la estética, aunque bien cierto es que muchos de sus discípulos aplicaron la fenomenología a cuestiones de estética, como Geiger, Ingarden o Conrad. Algo similar hizo Ortega. Las páginas que efectiva y propiamente dedicó Husserl a estética son pocas y muy dispersas, y en todo caso se podría hablar de la existencia en su obra de una estética fragmentaria y problemática ${ }^{5}$. Pero no es esto lo que nos interesa, porque no fue la estética fenomenológica de Husserl, en el caso de existir, lo que actuó sobre la filosofía del arte de Ortega, sino que lo que nos importa es la apropiación estética que hizo Ortega de los fundamentos filosóficos fenomenológicos establecidos por Husserl. Analizar esa traslación de la filosofía fenomenológica de Husserl a

\footnotetext{
2 Ortega y Gasset, J., Adán en el paraíso (1910), OC, II, 2004, p. 62.

3 Ibid.

4 En general, la fenomenología de Husserl es fundamental para entender el pensamiento de Ortega. Véase la detallada exposición y resumen del estado de la cuestión que presenta SAN Martin, J., La fenomenología de Ortega y Gasset, Madrid, Biblioteca Nueva, 2012, pp. 17-50. Otros trabajos para estudiar la presencia de la fenomenología de Husserl en la obra de Ortega: Silver, Ph., Fenomenología y Razón Vital. Génesis de "Meditaciones del Quijote» de Ortega y Gasset, Madrid, Alianza, 1978, passim; CERezo, P., La voluntad de aventura. Aproximamiento crítico al pensamiento de Ortega y Gasset, Barcelona, Ariel, 1984, pp. 197-255, 263-295; SAN MarTín, J., Ensayos sobre Ortega, Madrid, Uned, 1994, pp. 76-102, 123-131, 161-246; SAN MARTín, J., Fenomenología y cultura en Ortega. Ensayos de interpretación, Madrid, Tecnos, 1998, pp. 52-66, 71-90, 115-130; Ferrari Nieto, E., «Filósofos alemanes en la circunstancia de Ortega: referencias en busca de un espacio propio», en: Éndoxa, 25 (2010), 267-278, pp. 270-273.

5 Cfr. Steinmetz, R., L'esthétique phénoménologique de Husserl. Une approche contrastée, Paris, Kimé, 2011, pp. 7-20.
} 
la estética efectuada por Ortega es el cometido de este trabajo. La prueba de la fundamentación fenomenológica de la estética de Ortega no es otra que la comprensión orteguiana del arte como epoché y reducción eidética. Por tanto, el objetivo final de los análisis contenidos en este trabajo es llegar a esta idea tan fenomenológica del arte expuesta por Ortega. Ahora bien, dado que la deshumanización es el concepto central de la estética orteguiana, será el estudio de este concepto el hilo conductor que nos guiará hacia la demostración de la naturaleza fenomenológica de la filosofía del arte de Ortega.

En La deshumanización del arte de 1925 y refiriéndose al arte de vanguardia de principios del s. XX, Ortega confiesa que «las direcciones particulares del arte joven me interesan mediocremente, y salvando algunas excepciones, me interesa todavía menos cada obra en singular» ${ }^{6}$. Lo que sí le parece «importante es que existe en el mundo el hecho indubitable de una nueva sensibilidad estética», es decir, «una nueva intención del arte» (DA 857, 873). El arte concreto de vanguardia es para Ortega una manifestación material de lo verdaderamente relevante, que es una nueva forma de comprender el arte basada en la idea de deshumanización. En efecto, escribe, «buscando la nota más genérica y característica de la nueva producción encuentro la tendencia a deshumanizar el arte» (DA 857). Ahora bien, la pregunta por el arte deshumanizado de vanguardia equivale realmente para Ortega a la pregunta por la esencia del arte. De hecho Ortega ya se había planteado en 1914 esta misma cuestión y había respondido también con la idea de deshumanización, sólo que entonces no empleaba este término sino «irrealización» o «desrealización»: «El arte es esencialmente irrealización» (EEP 678), había escrito en el Ensayo de estética de 1914, texto en el que no casualmente aparecen, al tiempo, este concepto definitorio de la naturaleza del arte y la base fenomenológico/husserliana de la estética de Ortega. El ser del arte es la deshumanización. Pero arte deshumanizado es igual a arte desrealizado o irrealizado. Además, Ortega añade en 1925 que «estilizar es deformar lo real, desrealizar. Estilización implica deshumanización. Y viceversa, no hay otra manera de deshumanizar que estilizar» (DA, 860). En suma, esto significa que estilizar, desrealizar o irrealizar y deshumanizar son términos equivalentes. Ahora bien, dado que estilizar es artizar, o sea, hacer de los elementos propiamente estéticos lo sustancial del arte, decir «arte deshumanizado» o "arte desrealizado» vale lo mismo que decir «arte artístico» (DA 850, 853). Los términos «deshumanizar» y «desrealizar» pueden ser sinónimos sólo si se parte, como hace Ortega, de la identificación entre «realidad» y «realidad humana» o «realidad vivida», la cual es posibilitada por la tesis orteguiana de la vida humana como realidad radical, esto es, la afirmación de que toda realidad no es sino en una vida humana. La vida humana, la vida de cada uno, es el fundamento metafísico — raíz— de todo lo real, porque es «el

6 Ortega y Gasset, J., La deshumanización del arte (1925) (en adelante: DA, insertado en el texto, salvo si se cita en nota), OC, III, 2005, p. 857. 
ámbito donde todo lo demás se da —donde lo hallo o lo hay» ${ }^{7}$. Además, como «toda otra cosa y modo de ser lo encuentro en mi vida, dentro de ella», entonces «en ella todo lo demás es y es lo que sea para ella, lo que sea como vivido» ${ }^{8}$. Por tanto, ya que toda realidad es realidad sólo en una vida humana, «realidad» equivale lisa y llanamente a «realidad humana o vivida». Por ello «en la escala de las realidades corresponde a la realidad vivida una peculiar primacía que nos obliga a considerarla como «la» realidad por excelencia», declara Ortega, e inmediatamente precisa que «en vez de realidad vivida, podíamos decir realidad humana» (DA 856). Realidad por tanto se reduce a realidad vivida o humana, esto es, a la realidad que tiene cualquier cosa en tanto es vivida por un sujeto concreto: «Son humanas todas las realidades - mujer, paisaje, peripecia- cuando ofrecen el aspecto bajo el cual suelen ser vividas» (DA 856). Sólo esta reducción de realidad a realidad humana o vivida permite la asimilación entre desrealizar y deshumanizar.

Desrealizar es liberar a lo real de su carga de realidad para convertirlo en irrealidad. ¿Qué queda de las cosas una vez desrealizadas?. Ya que no es su realidad, queda su irrealidad o virtualidad, esto es, su aspecto ideal. Lo desrealizado tiene un tipo de existencia irreal, virtual o ideal, entendiendo aquí por «ideal» no el modelo perfecto, sino lo que tiene sustancia de idea y no de realidad: «Esta contraposición al carácter de realidad es el significado específico de la palabra "idea". Lo ideal es, propia y rigorosamente hablando, lo irreal»". Lo desrealizado es lo mismo que era antes de la desrealización, el objeto concreto, sólo que ahora está desrealizado o idealizado, descargado de su realidad vivida y vivido como una irrealidad o virtualidad. Si tenemos presente que el ser del arte, una vez practicada la desrealización que lo define esencialmente, es la irrealidad, entonces resulta patente la distinción radical entre arte y realidad. La estética de Ortega por tanto se fundamenta sobre una contraposición arte/ realidad que finalmente es una diferencia ontológica esencial entre irrealidad — arte - y realidad: «El objeto artístico sólo es artístico en la medida en que no es real» (DA 851). En medio de la realidad, se abre el universo ontológicamente diferente de la irrealidad del arte, una «isla imaginaria que flota rodeada de realidad por todas partes» ${ }^{10}$, una isla ingrávida, de carácter virtual (DA 865). La irrealidad artística y lo real son tan distintos que constituyen mundos herméticos e incomunicados, algo que Ortega reconoce en el arte de vanguardia, en el que «el pintor ha cortado el puente y quemado las naves que podían transportarnos a nuestro mundo habitual. Nos deja encerrados en un universo abstruso» (DA 858).

7 Ortega y Gasset, J., Principios de metafísica según la razón vital (1932/1933), OC, VIII, 2008, p. 642.

8 Ortega y Gasset, J., ¿Qué es filosofía? (1929), OC, VIII, p. 345.

9 Ortega y Gasset, J., Para dos revistas argentinas (1924) (en adelante ARG, insertado en el texto, salvo si se cita en nota), OC, III, p. 670.

10 Ortega y Gasset, J., Meditación del marco (1921) (en adelante: MM, inserto en el texto), El Espectador III, OC, II, p. 434. 


\subsection{La obra de arte como metáfora e irrealidad}

Asimismo, Ortega considera que desrealizar —o sea, deshumanizar, irrealizar o estilizar/artizar - es lo mismo que metaforizar. Por eso «objeto estético y objeto metafórico son una misma cosa, afirma Ortega, o bien, que la metáfora es el objeto estético elemental, la célula bella» (EEP, 673). Afirmar como hace Ortega que la naturaleza ontológica del arte es la irrealidad es lo mismo que sostener que es metáfora. Ahora bien, Ortega advierte que «el término "metáfora" significa a la par un procedimiento y un resultado, una forma de actividad mental y el objeto mediante ella logrado»(EEP 673). Esto significa que el concepto

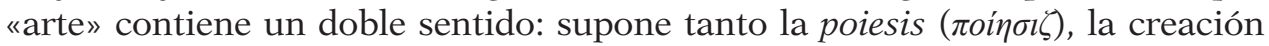
o acto productivo, que consiste en la «operación de deshumanizar» (DA 859) o metaforizar, como el resultado de la misma, el objeto producido, la obra de arte, que es entonces un objeto deshumanizado o desrealizado, o sea, una metáfora, una irrealidad, idealidad o virtualidad. En palabras de Ortega: «La esencia del arte es la creación de una nueva objetividad nacida del previo rompimiento y aniquilación de los objetos reales» (EEP 678). Por un lado, el arte es actividad, «rompimiento y aniquilación de los objetos reales», o sea, desrealización o metaforización (irrealiza lo real). Evidentemente desrealiza lo real pues qué otra cosa puede des-realizar sino aquello que es real. La actividad (desrealizadora) del arte sólo se puede practicar sobre la materia de la realidad, siempre presupuesta por la creación artística aunque sea para aniquilarla —desrealizarla. Por otro lado, el arte es el objeto fruto de esa actividad, la «creación de una nueva objetividad», una irrealidad, la obra de arte (realiza la irrealidad). Heidegger sostiene que "pretende encontrar la esencia del arte allí donde el arte sin duda impera (walten)», y por ello, tras preguntar «¿dónde y cómo hay arte?», responde: «El arte es (se presenta) esencialmente (west) en la obra de arte» ${ }^{11}$. Previa desrealización de lo real, añadiría Ortega, porque sin irrealización de lo real no hay obra. Mediante esa poiesis desrealizadora que define a la creación artística, el arte produce, pone en presencia, realiza, un objeto nuevo y distinto, extraño a la realidad de la que parte: la irrealidad o metáfora que es la obra de arte. El arte, pues, no consiste en la «ficción de realidades humanas» (DA 852), es decir, no se subordina a lo real; al contrario, consiste en la irrealidad realizada, de modo que lo esencial es la propia ficción, el elemento artístico. Molinuevo confirma que en Ortega el arte «no es la ficción de una realidad, sino la realidad — realizaciónde la ficción» ${ }^{12}$. La obra de arte es por tanto, según Ortega, "un nuevo objeto de calidad incomparable», una irrealidad novedosa respecto de la realidad que hallamos ante nosotros realizada, como «absoluta presencia» (EEP 671).

Eso es el arte, la creación y la nueva objetividad metafórica o irreal o virtual creada, o sea, la obra de arte. Según algunos de los más significativos ejemplos

11 Heidegger, M., Der Ursprung des Kunstwerkes (1935), Holzwege, Gesamtausgabe, Band 5, Frankfurt a. M.. Klostermann, 1977, pp. 1s.

12 Molinuevo, J. L., «Estudio introductorio» a J. ORTEga y Gasset, El sentimiento estético de la vida (Antología), Madrid, Tecnos, 1995, p. 35. 
de obras de arte que presenta Ortega ${ }^{13}$, el puente, rosa o ciprés representados en la obra no son el puente, rosa o ciprés reales, sino esos mismos objetos ya irrealizados o virtualizados, esto es, metamorfoseados/deformados o metaforizados (artizados): «No se trata de pintar algo que sea por completo distinto de un hombre, o casa, o montaña, sino de pintar un hombre que se parezca lo menos posible a un hombre, una casa que conserve de tal lo estrictamente necesario para que asistamos a su metamorfosis» (DA 859). En el cuadro de Regoyos «el puente no es, en verdad, un puente, ni humo el humo, ni campo la campiña. Todo en él es pura metáfora, todo en él goza de una existencia meramente virtual» (MM 434). El ser de lo metafórico como tal —el ser de la obra de arte por tanto- no es ser algo realmente sino serlo irrealmente, ser como. En la metáfora "la mejilla de la amada es una rosa», la mejilla no es realmente una rosa, sino que es como una rosa, o sea, que lo es virtual, irreal, ideal o metafóricamente: «El ser rosa la mejilla era sólo metafórico; no era un ser en el sentido de real, sino un ser en el sentido de irreal», de manera que la metáfora, "el ser como no es el ser real, sino un como-ser, un cuasi-ser; es la irrealidad como tal» (TEA 839). La metáfora — sustancia del arte- es virtualidad, idealidad o irrealidad. En 1909 ya había escrito que estos objetos de la obra no son verdad ni mentira, sino verosimiles, es decir, poseen «una existencia intermedia, semi-verdad, semi-error», pues, añade Ortega, «lo verosímil se presenta a la vez como no verdadero y no falso ${ }^{14}$. No es mentira decir que el puente pintado en ese paisaje es un puente, pero tampoco es verdadera o realmente un puente. Ortega escribe sugerentemente que el puente - como el resto de objetos representados en el cuadro- «está sin estar» (MM 434). Ni es un puente real, verdadero, ni es un puente falso, un engaño de puente. Es un puente artístico, esto es, metafórico, irreal o verosímil, que está virtualmente sin estar realmente. La metáfora de un puente, o sea, un puente real metaforizado, lo que implica creación de ese nuevo e irreal puente a partir de la desrealización o aniquilación de la realidad puente. Sólo una vez desrealizados y quebrada su realidad se pueden constituir esos objetos artísticos virtuales. La mejilla/rosa o el ciprés/llama no existen realmente. Sólo son virtualmente en la metáfora de la obra de arte que los ha traído al ser. El ciprés/llama por tanto no es una «representación de» otra cosa. Toda obra de arte representa algo, pero lo que representa es a ella misma. El ciprés/llama sólo es representación de sí mismo, puesto que sólo existe en el verso que canta que el ciprés é com l'espectre d'una flama morta (EEP 673). Ese verso es la presencia absoluta del ciprés/llama. Lo mismo ocurre con el puente pintado en el cuadro y con la mejilla/rosa. Son presencias absolutas en la obra

13 El ciprés/llama del verso que dice que el ciprés e com l'espectre d'una flama morta (EEP 673); la mejilla/rosa del poeta que las iguala en un verso: ORTEGA y GASSET, J., Idea del teatro (1946) (en adelante: TEA, inserto en el texto, salvo si se cita en nota), OC, IX, 2009, p. 839; el paisaje kilométrico de Regoyos — con un río, un ferrocarril o un puente-que cabe en un cuadro de menos de un metro (MM 434); y la persona real concreta que en la obra teatral es (se transfigura en) Hamlet (TEA 840, 849).

14 Ortega y Gasset, J., Renan (1909), OC, II, pp. 39s. 
de arte, que sólo ahí existen y que surgen a partir de la metaforización de objetos realmente existentes — ciprés, llama, puente, rosa o mejilla.

\section{FundaMentos FENOMENOLÓGICOS DEL ARTE COMO DESREALIZACIÓN}

\subsection{La vida como ejecutividad: cogito lebendig}

Pero cómo es posible que una mejilla sea una rosa o un ciprés llama. No hay mejillas ni cipreses que sean realmente rosas ni llamas. La mejilla real no puede ser rosa, pero sí puede serlo la mejilla virtual o metafórica. Hay que desrealizar o metaforizar por tanto esos objetos reales para que, una vez triturada y destruida su realidad, se puedan crear esos nuevos, extraordinarios y virtuales o irreales objetos artísticos. Para identificar lo que realmente no es idéntico y crear mediante esa fusión un objeto nuevo, la obra de arte, es necesario desrealizar o metaforizar la realidad de que se parte. Pero insistimos: cómo son posibles esos objetos artísticos y virtuales, o sea, cómo es posible el arte. Para responder a esta pregunta hay que responder con rigor a la pregunta por la desrealización. En qué consiste exactamente, cómo se lleva a cabo. La respuesta la encontró Ortega en la fenomenología husserliana. En ella descubrió Ortega los fundamentos filosóficos del arte como desrealización. Recordemos que realidad equivale según Ortega a realidad humana o vivida, de modo que la realidad de algo es lo que es en una vida humana concreta, o sea, lo que es ese algo como vivido por un sujeto humano. Pero entonces podemos precisar que en la filosofía orteguiana desrealizar es lo mismo que desvivir. Para desrealizar hay que penetrar en la vida humana. Pero qué es vivir.

Ortega extrae su concepto de vida a partir de la idea husserliana de la actitud natural de la conciencia o conciencia natural y ejecutiva expuesta en 1913 en varios pasajes de Ideen $I^{15}$. Ortega asumió muy pronto esta tesis de Husserl y la presentó bajo su noción de vida como ejecutividad en Sobre el concepto de sensación de 1913 y en el Ensayo de estética a manera de prólogo de 1914'16. Llama la atención el hecho de que en el Ensayo de estética Ortega exponga su concepto de vida como ejecutividad claramente deducido de aquella descripción husserliana de la conciencia natural, y, al tiempo, su primera declaración de la

15 Husserl, E., Ideen zu einer reinen Phänomenologie und phänomenologische Philosophie, (en adelante: Ideen I, insertado en el texto, salvo que se cite en nota), Husserliana III/I, Hrsg. v. K. Schuhmann, Den Haag, Nijhoff, 1976, § 28, 35, 80, 92; pp. 59, 73, 179, 214. Cfr. Cerezo, P., La voluntad de aventura, pp. 201ss, 218ss; Silver, Ph., Fenomenología y Razón Vital, pp. 99, 114ss.

16 El evidente origen husserliano de todas estas tesis acerca de la conciencia natural, la conciencia de, y el método de la epoché y la reducción, queda confirmado por el hecho de que en Sobre el concepto de sensación de 1913 expone Ortega estas ideas justo después de la publicación de Ideen I de Husserl y con el fin de explicar «lo que entendemos, siguiendo a Husserl, por fenomenología» (OrTega y Gasset, J., Sobre el concepto de sensación (1913) (en adelante: CS), OC, I, p. 633). 
actividad artística como desrealizar o desvivir. Esto muestra indudablemente el nexo entre esa idea de vida derivada de Husserl y su propia comprensión personal del arte como desrealización. La noción orteguiana del arte como deshumanización no podrá entenderse si no se pone en contacto con la tesis fenomenológica de vida. Pues bien, la conciencia natural husserliana es conciencia viviente (cogito lebendig), que consiste en ejecutar (vollziehen) los actos de conciencia (cogitos o vivencias) ${ }^{17}$, es decir, en vivirlos actualmente, sin necesidad de reflexionar sobre el acto (cogito) y lo vivido en él (cogitatum): «En el natural dejarse vivir (natürlichen Dahinleben), escribe Husserl, vivo constantemente en esta forma fundamental de toda actual, enuncie o no el cogito, reflexione o no sobre el yo y el cogitar. Si lo hago, hay un nuevo cogito viviente (cogito lebendig) que no es reflexionado por su parte y, por tanto, no es para mí objetivado» (Ideen I, § 28, p. 59). Esa conciencia natural o conciencia viviente que es un ejecutar actos de conciencia sin autorreflexión predicativa de ello, sin declararlo, eso es vida, vivencias de la conciencia llevándose a cabo. Vivir es ejecutar actos de conciencia (vivencias) y mientras los vivo no enuncio predicativamente ese cogito lebendig; cuando lo hago, vivo el acto ejecutivo de conciencia de reflexionar sobre un cogito lebendig, y entonces esta vivencia reflexiva es el nuevo cogito lebendig que ejecuto y vivo.

La vida natural husserliana se singulariza por el carácter ejecutivo de sus actos. Y Ortega en 1913 insiste en que "hay una "manera natural" de efectuar los actos de conciencia, cualesquiera que ellos sean. Esa manera natural se caracteriza por el valor ejecutivo que tienen esos actos» (CS 631). Esta manera natural (ejecutiva) de efectuar los actos de conciencia o vivencias es vivir. En ese concepto husserliano de vida como cogito lebendig, como ejecución de actos de conciencia, se encuentra según Cerezo el antecedente más inmediato de la idea orteguiana de vida ${ }^{18}$. Tengamos presente, de acuerdo con Cerezo, que Ortega en Sobre el concepto de sensación, texto de 1913 en el que expone su comprensión de la fenomenología tras la lectura de las recién publicadas Ideen I, usa por primera vez el término ejecutividad (CS 631) con el que describe esencialmente la vida para traducir el concepto husserliano que define la actitud natural de la conciencia: vollziehen ${ }^{19}$. Esto ratifica, por una parte, la raíz fenomenológica de ese concepto, y, por otra y más importante, que el concepto orteguiano de «vida humana» se origina en el concepto de conciencia natural y ejecutiva de Husserl. Ortega entiende la noción de vida desde este cogito lebendig husserliano, cuya característica sustancial es la ejecutividad, verdadera esencia de la vida. Vida y conciencia (natural, viviente, ejecutiva) son inseparables. Por tanto, vida

17 Husserl describe el acto $(A k t)$ como una «cogitatio, una vivencia de conciencia (Bewußtseinserlebnis)» (Ideen I, § 35, p. 71). Ortega, con Husserl, confirma que la «pura conciencia» es «el plano de las vivencias» (CS 634). Por eso la fenomenología, según Husserl, «quiere ser una ciencia descriptiva de las esencias de las vivencias puras trascendentales en actitud fenomenológica» (Ideen I, § 75, p. 132).

18 Cerezo, P., La voluntad de aventura, p. 219.

19 Ibid., p. 209. 
según Ortega es ejecutividad, llevar a cabo actos de conciencia o vivencias: pensar, amar, percibir, etc. Vivir, en tanto ejecutar vivencias, significa estar entregado absolutamente a ese actuar, comprometido plenamente con él, puesto sin reservas y totalmente en él: "Cuando percibimos algo y es el percibirlo bien lo que nos interesa, vivimos definitivamente en el acto de percepción» (CS 627). Vida es vivencia, ejecución de actos de conciencia, y lo propio de un «acto» es llevarlo a cabo, ejecutarlo (vivirlo ejecutivamente). La conciencia natural (ejecutiva) de la vivencia amorosa p.e., es decir, vivir (ejecutivamente) un acto de conciencia amoroso, consistirá en amar: "Cuando amamos nuestra conciencia vive sin reservas en el amor»(CS 631). Ortega confirma que "a esta eficacia de los actos cuando nuestra conciencia los vive en su actitud natural y espontánea llamábamos el poder ejecutivo de aquéllos»(CS 631). Vivir es ejecutar, llevar a cabo el acto, entregado a él. Vivir el amor es amar, vivir la percepción es percibir. Vida es p. e. el dolor doliendo, la conciencia ejecutando el acto de dolor, o sea, la conciencia doliéndose. Cuando Ortega ha afirmado antes que la realidad vivida es la realidad por excelencia, quiere decir que, según este último ejemplo, la realidad (verdad) del dolor no es sino ese dolor ejecutivo o vivido. En la conciencia doliéndose, viviendo el dolor, ahí está la realidad del dolor. En Ensayo de estética llama «intimidad» a esta vida ejecutiva ( la verdadera intimidad que es algo en cuanto ejecutándose») y luego precisa que «la intimidad es el verdadero ser de cada cosa» (EEP 670).

Ahora bien, realmente sólo yo vivo el percibir, el juzgar, el amar, el doler, etc. Vivir, ejecutar vivencias o actos de conciencia en los que se da la realidad de lo vivido, es algo que sólo hace el yo, el yo concreto. Según Husserl: «Todo cogito, todo acto en un cierto sentido, se caracteriza por ser un acto del yo, un acto que procede del yo, que vive en él actualmente» (Ideen I, § 80, p. 178). Sólo yo vivo el dolor, el amor, el percibir o el pensar. El dolor que duele, la realidad del dolor, el dolor doliente, sólo es el dolor que yo vivo (ejecuto) desde dentro. El doler real sólo está en el dolor vivido/ejecutado por un yo. El dolor del otro - del tú, del él- es dolor no ejecutivo, no vivido, sino dolor desde fuera, contemplado, y por tanto no es verdadero dolor, el que duele. Este dolor sólo será dolor verdadero para ese tú en tanto que es yo que lo vive; para mí siempre será dolor/objeto, nunca dolor ejecutivo. Cuando veo al otro dolerse, no hay para mí dolor (por dentro); sólo hay dolor objetivado (por fuera). La vida en rigor sólo es cosa del yo. En las vivencias de la conciencia, en el cogito, es el yo - no tú ni él- el que vive en acto. Sólo yo «ejecuto un acto de conciencia (Ich vollziehe einen Bewußtseinsakt)» (Ideen I, § 35, p. 73). Vivir sólo vive estrictamente el yo, y vive ejecutando actos de conciencia en primera persona, entregado sin reservas a la ejecución de los actos que constituyen la vida: «El yo, escribe Husserl, vive en esos actos» (Ideen I, § 92, p. 214). Por eso Husserl considera que la actitud natural de la conciencia, la vida en suma, sólo puede ser descrita mediante expresiones en primera persona o Ichrede y esto significa que los seres humanos vivimos «representándonos, juzgando, sintiendo, queriendo en actitud natural», es decir, que yo — cada uno- represento, juzgo, siento o quiero (Ideen I, $\S 27$, p. 56). La vida consiste en la realización de estas Ichrede o ejecuciones en 
primera persona: «En todos esos actos estoy yo presente, actualmente presente» (Ideen I, § 80, p. 179). Con Husserl, también Ortega en el Ensayo de estética caracteriza la vida como ejecutividad como realización de actos en primera persona. El andar ejecutivo, vivir el andar, se da en el "yo ando», no en el "él anda», pues «el andar de "él" es una realidad que percibo por los ojos» (EEP 667), y no una realidad que vivo o ejecuto. Ortega concluye que «toda una clase de verbos se caracteriza por ser su significación primaria y evidente la que tienen en primera persona» (EEP 668).

\subsection{La conciencia de como plano fenoménico de objetividad primaria}

Ahora bien, al vivir, al ejecutar la conciencia natural, en el cogito lebendig, y sin que seamos conscientes, se da un plano de objetividad al que sólo podemos acceder mediante, primero, la suspensión del vivir ejecutivo de la conciencia natural (epoché), y, segundo, mediante la reflexión (reducción) ${ }^{20}$. En este trabajo asumimos la diferencia entre epoché y reducción como dos pasos necesarios y relacionados del método fenomenológico, pues ni hay reducción sin epoché ni tiene sentido - aunque pudiera existir en abstracto- una epoché que no desemboque en la reducción, razón por la que no compartimos la tesis de Patočka que, una vez afirmada la distinción entre ambas, considera que «sería posible una fenomenología sin reducción, pero no sin epoché» ${ }^{21}$. A ese plano más radical y primario apela Ortega siguiendo a Husserl para explicar la desrealización que nos ocupa. Analicemos en qué consiste. El vivir ejecutivo contiene un ámbito de sentido que, mientras vivimos ejecutivamente no nos es objeto, de modo que sólo nos es presente objetivamente mediante epoché y reducción eidética. La conciencia ejecuta actos, vive, pero todo cogito lleva su cogitatum. Todo lo vivido, lo dado a la conciencia ejecutivamente, sin darnos cuenta, le es primaria, preteórica y originariamente a la conciencia algo: este algo se da en la región de lo puramente concienciado por la conciencia al vivir cada concreta realidad y constituye ese plano radical que Ortega denomina objetividad primaria de las cosas (CS 633). Este «algo» es lo que las cosas son antes que nada: lo que puramente se aparece de ellas a la conciencia, o sea, el fenómeno, el cual, según definición de Ortega, es «lo absolutamente patente, lo

20 Cfr. Husserl, E., Die Krisis der europäischen Wissenschaften und die transzendentale Phänomenologie, Husserliana, Band VI, Den Haag, Nijhoff, 1976, § 41-42, pp. 154ss.

21 Ратос̌ка, J., "Epoché et réduction» (1975), Qu'est-ce que la phénoménologie, ed. de E. Abrams, Grenoble, J. Millon 1988, p. 260. Para una detallada exposición de la relación entre epoché/reducción: PATOčKa, J., op. cit., pp. 249-261; SAN MARTín, J., La estructura del método fenomenológico, Madrid, UNED, 1986, pp. 26-36. Cfr RichIR, M., «Monadologie transcendentale et temporalisation», Husserl Ausgabe und Husserl Forschung, ed. S. Ijsseling, Phaenomenologica 115, Dordrecht, Kluwer, 1990, p. 170; Hoyos, G., «Zum Teleologiebegriff in der Phänomenologie Husserls», Perspektiven transzendental-phänomenologischer Forschung, Hrsg. V. U. Claesges und K. Held, The Hague, Nijhoff, 1972, p. 67; Held, K., Lebendige Gegenwart, The Hague, Nijhoff, 1966, pp. 17, 63, 144. 
que no pretende ni puede ser más que tal y como aparece» ${ }^{22}$. El fenómeno es lo que aparece puramente ante la conciencia, sin construcciones ni teorías, sin añadir ni quitar nada a lo estrictamente presente ante la conciencia; es aquello cuyo ser consiste en aparecer. Así que una vez suspendido el vivir en el que se da implícitamente el fenómeno y patentizado éste mediante la reducción fenomenológica, se trata de reducirse a su eidos, a su esencia (reducción eidética ${ }^{23}$. En esto consistirá la fenomeno-logía: hacer epoché del vivir y luego reducción eidética hacia la esencia del fenómeno obtenido tras la epoché.

Veo una mesa. La veo desde una perspectiva y hay muchos aspectos de ella que no me aparecen. Esa mesa real que veo no es tal y como me aparece, pero sí lo es la conciencia de esa mesa. Mi conciencia de la mesa es tal y como se me aparece ante la conciencia y no es nada más, porque es precisamente «lo que» se me aparece de la mesa. El fenómeno husserliano no es sino esta conciencia de. Nada, ninguna realidad, nos es sin que sea a nuestra conciencia algo primariamente: lo que puramente se presenta o aparece ante nuestra conciencia, lo que inmediata y antepredicativamente es la cosa en cuestión para la conciencia. Este plano fenoménico, donde todo es nada más tal y como aparece, es la objetividad primaria de las cosas, lo que mínimamente son, lo que nos son las cosas en tanto que se nos aparecen puramente ante la conciencia. Ahora bien, «este plano de objetividad primaria, en que todo agota su ser en su apariencia (fainómenon), es la conciencia, no como hecho tempoespacial, no como realidad de una función biológica o psicofísica adscrita a una especie, sino como conciencia de» (CS 633). Del brillo metálico, según Ortega, podemos tener muchas perspectivas, pero todas ellas presuponen lo que nos es el brillo metálico como fenómeno, es decir, "lo que veo en cuanto y sólo en cuanto que lo veo", la «conciencia de brillo metálico»(CS 634). Lo que Ortega descubre en Husserl, y que por eso llama "principio fenomenológico», es que «los objetos son, antes que reales o irreales, objetos, es decir, presencias inmediatas ante la conciencia» (CS 634). Todo lo que se nos da como mínimo es tal y como se nos da, tal y como es inmediatamente presente ante la conciencia, o sea, precisa Ortega, «el ser real, el ser trascendente, podrá ser de otro modo que como yo pienso que es; pero lo que yo pienso es tal como lo pienso» (CS 633). El ser radical de las cosas, su objetividad primaria, lo que son para nosotros antes de toda

22 Ortega y Gasset, J., Sistema de la psicología (1915) (en adelante: SP, insertado en el texto, salvo que se cite a en nota), OC, VII, 2007, p. 479.

23 No es intención de este trabajo detallar todos los entresijos técnicos de la fenomenología que separan las diversas reducciones. Baste decir que tras la epoché, la detención del vivir ejecutivo, lo primero es reducirse al fenómeno, a lo que se me aparece (reducción fenomenológica), para luego reducirse al eidos de lo que se me aparece (reducción eidética). Esto significa que "cuando adopto una mirada fenomenológica, dejo de interesarme en ese gran cogitatum, en ese mundo objetivo y empiezo a interesarme acerca de cómo ese mundo objetivo me es dado, como se me aparece, o sea, empiezo a interesarme acerca del fenómeno en tanto que tal: esa es la reducción fenomenológica» (РАTоčKA, J., Introducción a la fenomenología (1969-1970), Barcelona, Herder, 2005, p. 138). Por tanto, sepamos que la reducción eidética a la que nos referiremos presupone, además de la epoché, la reducción fenomenológica. 
interpretación, su significado originario consiste en lo que son puramente para nuestra conciencia como presencias inmediatas ante ella, nuestra conciencia de ellas. Esta objetividad primaria es sin duda la cosa misma que buscaba Husserl. Ortega añade que las ciencias explicativas «parten del fenómeno y lo abandonan por objetos reales» (CS 634), es decir, por realidades no manifiestas - no fenoménicas- con el fin de explicar el fenómeno. Esas realidades que laten tras el patente fenómeno del brillo metálico p. e. (ondas, partículas, fisiología de la percepción, etc.), objeto de las ciencias explicativas (física, fisiología o psicología), son construcciones, elementos secundarios frente a la presencia primaria del brillo. Sólo la fenomeno-logía, ciencia descriptiva de fenómenos y no de realidades, se reduce a la esencia del fenómeno, a la objetividad primaria estrictamente presente ante la conciencia; la fenomenología se limita a describir la «conciencia de brillo metálico» (CS 634). La fenomenología husserliana ha convertido por tanto la captación de las esencias de las cosas que constituye la meta de la filosofía, en captación de las conciencias de, reduciendo la filosofía a la descripción de lo aprehendido o intencionado como tal ${ }^{24}$. Por eso, Ortega puede escribir que «la fenomenología es descripción pura de esencias» y que «el tema cuyas esencialidades describe es todo aquello que constituye la conciencia» (CS 632). Se trata de captar lo que nos son puramente las cosas para la conciencia, su presencia inmediata ante ella, lo concienciado. Esos «lo que» son las esencias que persigue la filosofía.

A esta conciencia de las cosas la llama Ortega también, siguiendo a Husserl, «intenciones significativas» o «conceptos» (SP 486). Ortega aclara que Husserl distingue "actos de "intención significativa" (Bedeutungsintentionen Akte) y actos de "cumplimiento de la significación" (Bedeutungerfüllende Akte) ${ }^{25}$, actos en que yo me refiero a algo y actos en que ese algo me es dado directa e inmediatamente» (SP 486). Los actos en que se cumple el significado, explica Ortega, son la percepción y la representación: cuando percibo el objeto lo tengo ante mí presente y cuando tengo una representación del mismo, mediante una fotografía o un recuerdo, está presente de forma ausente (SP 483s). Pero además de presente o ausente (representado), el objeto puede estar también intencionado significativamente, o sea, mentado. P. e., explica Ortega, «la estrella más lejana de la tierra» o «la ameba primera que existió» ni me están presentes ni representadas, pero «sé, que ahora entiendo esos nombres y que con ellos me refiero a ciertos objetos únicos e inconfundible los cuales no están presentes ante mí, ni siquiera como ausentes me son representados, sino que ellos se me ofrecen precisamente y sólo como "objetos a que yo me refiero", sin más. Tenemos, pues, sobre presencia y ausencia, el modo de referencia, en que en mí no hay del objeto sino mi referencia a él»(SP 485s). Lo que hay entonces del

${ }^{24}$ Tran-Duc-Thao ha insistido en esta tesis al advertir que «el análisis eidético era un análisis intencional que se ignoraba a sí mismo» (Tran-Duc-Thao, Fenomenología y materialismo dialéctico, Buenos Aires, Nueva Visión, 1971, p. 42).

25 Husserl, E., Logische Untersuchungen: Untersuchungen zur Phänomenologie und Theorie der Erkenntniss, Husserliana XIX/1, her. v. U. Panzer, Den Haag, Nijhoff, 1984, I, § 9, p. 44. 
objeto ante nosotros es sólo nuestra conciencia de él, nuestro referirnos a él, nuestro mentarlo. Estas menciones son esas ideas, conciencias de o intenciones significativas, o sea, lo mínimo, primario y más radical que nos es algo. El ser primario y preteórico para nuestra conciencia de las cosas equivale a nuestro referirnos a ellas. Por tanto «lo que» nos son las cosas originariamente ante la conciencia, su objetividad o esencia primaria, es un concepto y consiste en «lo que» intencionamos prerreflexivamente, lo puramente intencionado en el acto de intencionar significativamente. La conciencia de las cosas es el concepto primario que tenemos de ellas. Toda intención significativa lleva consigo un significado primario, que consiste en lo que primariamente es intencionado de la cosa, en el significado primario que tiene la cosa ante la conciencia, libre de toda construcción. Nada nos es por tanto sin que tenga un significado primario. Ortega distingue tres tipos de objetos. El primero, las cosas en que pensamos o vemos, pueden ser reales o ideales, pero todas tienen en común el hecho de ser el término de nuestros actos de conciencia. Están fuera de nuestra conciencia. El segundo, los actos en los que se nos dan tales cosas, que también están dentro de la conciencia. Finalmente, lo que pensamos de esas cosas, nuestras ideas de ellas, lo concienciado como tal, o sea, nuestras conciencia de ellas (ARG 670). Estas ideas «son realidades que acontecen en el alma del individuo, pero se diferencian de las sensaciones en que su contenido - lo ideado- es irreal $»^{26}$, de modo que, según Ortega, «no están ni fuera ni dentro de nosotros ni en parte alguna porque no son realidades. Esta contraposición al carácter de realidad es el significado específico de la palabra «idea». Lo ideal es, propia y rigorosamente hablando, lo irreal» (ARG 670). Su naturaleza es la idealidad, no son seres reales sino ideales. Esta idea, «lo que» pensamos de los objetos, lo concienciado en cuanto tal, está en el sujeto pero no es nada subjetivo, y por eso Ortega lo llama lo intrasubjetivo (PVA 171).

La conciencia de el dolor, nuestra intención significativa o mención del dolor, lo que nos es el dolor primariamente ante la conciencia, es el concepto originario del dolor, lo que nos es el dolor en el vivirlo primario del cogito lebendig. Todo lo que se nos da como vivido incluye un concepto así, aunque sin enunciar. Todo lo que nos es, lo mentamos. Por eso advierte Ortega que, aunque pueda parecer una "extraña forma de relación con los objetos», realmente es «la más frecuente en nuestra conciencia», pues, «¿cabe percibir el objeto sin mentarlo a la par o es la mención el modo elemental de la conciencia que va en todos sus actos, sean cuales quieran, como envainado o incluso?» (SP 486). Todos nuestros actos de conciencia se refieren al mundo real mediante estas ideas, menciones o conciencias de, que van incluidas y presupuestas en aquéllos, y que representan el significado primario de las cosas ante la conciencia. Por tanto, concluye Ortega, «los viejos, venerables y enigmáticos "conceptos", esa palabra sacramental de la filosofía, no vendrían a ser, en fin de cuentas, más

26 Ortega y Gasset, J., Sobre el punto de vista en las artes (1924) (en adelante: PVA), OC, V, 2006, p. 170. 
que esos actos de mención» (SP 486s). El concepto en Ortega, tras su acercamiento a la fenomenología, representa la primera y prerreflexiva conciencia -idea-que tenemos de las cosas, «lo que» puramente de ellas se nos aparece en la conciencia, es decir, lo que preteóricamente nos son. Los conceptos para Ortega son las intenciones significativas, consisten en el significado primario con que intencionamos las cosas, lo que primero e inmediatamente nos son. Aludiendo a Husserl, Ortega escribe que "pensar es un acto intencional, un acto por el que nos referimos a un objeto», y que «esta referencia consiste en la "significación": "árbol" es una significación por la que nos referimos al objeto así llamado» ${ }^{27}$. Al vivir, la conciencia experimenta las cosas reales. Sin darse cuenta, se refiere a ellas mediante esas intenciones significativas, conciencia de o conceptos: «Todo acto de conciencia es referencia a un objeto por medio de lo "intencional" del acto. El correlato del acto no es el objeto - por ejemplo, el sol de quien hablo-, sino aquel "objeto inmanente", aquel sentido por medio del cual pienso, me refiero al sol» (CS 636n). Eso intencional, el objeto inmanente, es decir, la objetividad o significado primario, es lo que nos es el sol en tanto presencia inmediata ante la conciencia. Es el sol como pura «conciencia de» o intención significativa. Por tanto, los actos de conciencia o vivencias, que siempre son referencias a objetos, se refieren a (piensan) esos objetos, seamos o no conscientes de ello, mediante intenciones significativas, conceptos o ideas, consistentes en lo que esos objetos son puramente para la conciencia, o sea, en nuestra conciencia de los objetos, en lo concienciado intrasubjetivo. Este lo que es la objetividad primaria de esos objetos. Esa objetividad, el sentido originario de las cosas, lo que nos son como puras presencias ante la conciencia, va presupuesta y no tematizada en todo nuestro experimentar objetos reales. El cogito lebendig vive ese eidos, no lo piensa. Todos nuestros contactos de conciencia con las cosas van como encapsulados en nuestras conciencias de. A esto apuntaba Ortega cuando decía que «no miramos con los ojos, sino al través o por medio de los ojos; miramos con los conceptos ${ }^{28}$.

\subsection{La postura inhumana de la fenomenología: epoché y reducción eidética}

En la vivencia ejecutiva del cogito lebendig lo vivido es intencionado ejecutivamente mediante una intención significativa o idea de la que no somos conscientes y que consiste en lo que la cosa vivida es como presencia inmediata ante la conciencia, su objetividad primaria. Ahora bien, esas objetividades primarias se dan en los actos de conciencia o vivencias, o sea, en la vida o vivir. En la conciencia en actitud natural, en tanto vida, están esas objetividades primarias, pero no se nos dan reflexivamente sino que sólo son vividas. Al vivirlas ejecutivamente no somos conscientes; solo las vivimos como realidad con la que estamos comprometidos. En la experiencia vivida o conciencia ejecutiva

27 Ortega y Gasset, J., Para un diccionario filosófico (1913), OC, VII, p. 344.

28 Ortega y Gasset, J., Meditaciones del Quijote (1914) (en adelante: MQ, inserto en el texto, salvo que se cite en nota), OC, I, pp. 788s. 
— cogito lebendig - del dolor, experimento — vivo - el dolor real. Cuando hay cogito lebendig hay dolor, dolor doliendo, y no conciencia de (imagen o concepto) el dolor. Mientras vivimos, no hay conciencia de; mientras hay conciencia natural, no se nos manifiesta el plano de las objetividades primarias. Cuando vivo algo, en el cogito lebendig, lo vivido se nos da como realidad, no como objeto, no como sentido. Entonces, usamos humana o naturalmente las ideas, escribe Ortega, «cuando con ellas pensamos las cosas» (DA 856), pero al hacerlo así no somos conscientes de ellas. Efectivamente, "Con las ideas, insiste, vemos las cosas, y en la actitud natural de la mente, no nos damos cuenta de aquéllas» (DA 867) ${ }^{29}$. Pero Ortega piensa, en clave fenomenológica, que es posible detener ese movimiento ejecutivo y quedarnos con (reducirnos a) eso vivido tal como se nos presenta inmediatamente ante la conciencia, con nuestra «conciencia de», con nuestra intención significativa primaria de eso vivido. Para reflexionar sobre ese acto ejecutivo del cogito lebendig y manifestar la objetividad primaria de lo vivido, para poder obtener — reducirse a - el sentido o intencionalidad de esa vida ejecutiva, hay que detener primero el vivir ejecutivo y convertirlo en vida contemplada. Por tanto, para lograr acceder a la conciencia de y captar la objetividad primaria que se da en ella hay que hacer epoché, detener el ejecutarse del cogito lebendig, suspender la conciencia natural del vivir. La vida es conciencia natural ejecutiva; por tanto desvivir (desrealizar) será detener el ejecutarse de la conciencia natural. Cuando dejamos de «vivir» (ejecutar) un acto para reflexionar sobre él, entonces ese acto «con todas sus consecuencias ejecutivas, con toda su afirmación de que algo real hay ante ella, quedará, por decirlo así, en suspenso» (CS 631). Sólo entonces se patentiza esa región latente de la conciencia de. Pues bien, según Ortega, «lo que hace de la fenomenología una novedad consiste en elevar a método científico la detención dentro de ese plano de lo inmediato y patente en cuanto tal, de lo vivido» (CS 634). Sólo mediante la suspensión de la ejecución de la vivencia de la conciencia se manifiesta la conciencia de latente en ella, lo vivido en tanto presencia inmediata ante la conciencia, la objetividad primaria. Una vez situados mediante epoché en ese plano de objetividad primaria que es la «conciencia de», se trata de practicar en él la reducción eidética para limitarse a su eidos, a lo que es vivido. La filosofía fenomenológica ha adoptado una postura inhumana y antinatural y ha girado hacia lo intrasubjetivo convirtiendo lo que era medio del pensar, la idea, la intención significativa u objeto inmanente, en su fin y objeto: «En vez de ser la idea instrumento con que pensamos un objeto, la hacemos a ella objeto y término de nuestro pensamiento» (DA 856). Y Ortega añade que

29 Ortega añade que «la tendencia natural nos lleva a creer que la realidad es lo que pensamos de ella, por tanto, a confundirla con la idea, tomando ésta de buena fe por la cosa misma» (DA 867). Es una actitud ingenuamente idealizadora de la realidad puesto que, sin conciencia, considera realidad lo que es idea. Esta propensión nativa a idealizar lleva al error porque realmente, según Ortega, «entre la idea y la cosa hay siempre una absoluta distancia. Lo real rebosa siempre del concepto que intenta contenerlo. El objeto es siempre más y de otra manera que lo pensado en su idea» (DA 867). 
«ya veremos [en el próximo apartado] el uso inesperado que el arte nuevo hace de esta inversión inhumana» (DA 856). Esta declaración confirma que Ortega comprende el arte desde la perspectiva fenomenológica del cambio de actitud de conciencia que lleva a practicar al epoché y la reducción.

\section{El ARTE COMO EPOCHÉ Y REDUCCIÓN}

\subsection{La conciencia de como lugar del arte: epoché y reducción espontáneas}

No es casual que en el Ensayo de estética de 1914, justo después de exponer la tesis fenomenológica del ser ejecutivo de la vida, Ortega plantee que el arte se localiza en la conciencia de, idea o lugar sentimental. Ambos factores son una prueba de la fundamentación fenomenológica de la estética que propone Ortega. Dado que "objeto estético y objeto metafórico son una misma cosa» (EEP 673), y que, por tanto, hablar sobre la metáfora y sobre el arte es lo mismo, entonces el análisis de la metáfora que presenta en el Ensayo será el hilo conductor para poder mostrarlo. La metáfora que estudia Ortega en este texto es el verso del poeta López Picó que dice que el ciprés e com l'espectre d'una flama morta. El objeto estético/metafórico ciprés/llama identifica dos objetos que realmente no son idénticos. Esa obra de arte, la metáfora ciprés/llama, es un nuevo objeto, irreal o virtual por supuesto, ya que realmente no hay identidad entre ciprés y llama. Ahora bien, precisa Ortega, «una vez advertidos de que la identidad no está en las imágenes reales», la metáfora "nos empuja a otro mundo donde por lo visto es aquélla posible», un «nuevo mundo donde los cipreses son llamas» (EEP 675). Ese mundo, el mundo donde únicamente son posibles el arte y la metáfora - como esencia del arte-, es el de lo intrasubjetivo, el plano de la conciencia de, algo que en este texto Ortega llama sentimiento o lugar sentimental. Situados por fin en este ámbito, podemos ya crear la metáfora (obra de arte) ciprés/llama porque, si bien sus imágenes reales se excluyen, se son opacas e impiden la transparente identidad entre ambas, sus conciencia de o lugares sentimentales hacen posible la identidad metafórico que da lugar a la obra de arte: «Tenemos, pues, un caso de transparencia que se verifica en el lugar sentimental de ambas. El sentimiento-ciprés y el sentimiento-llama son idénticos» (EEP 676).

Para acceder a este universo de posibilidades artísticas es necesaria la epoché. En efecto, «mientras se está ejecutando el acto vital mío de ver el ciprés, es este el objeto que para mí existe; qué sea yo en aquel instante constituye para mí un secreto ignorado» (EEP 676). Mientras hay ciprés, mientras lo vivo, no hay yo ni conciencia de, de modo que para llegar a ella hay que practicar la epoché, «será preciso que me sitúe de espaldas a la cosa ciprés, y desde ella mire hacia dentro de mí y vea el ciprés desrealizándose, transformándose en actividad mía, en yo» (EEP 676). A esto, «a lo que toda imagen es como estado ejecutivo mío, como actuación de mi yo, llamamos sentimiento» (EEP 676). Por 
tanto el arte, en cuanto que tiene que situarse en ese plano intrasubjetivo de la conciencia de, desrealiza, deshumaniza o desvive. Hacer esto significa suspender la realidad vivida, el cogito lebendig, y quedarse con la realidad contemplada, con nuestra conciencia de la realidad, lo intrasubjetivo, que es el nuevo objeto del arte. Ortega confirma que «la desrealización no se logra si no es por una supeditación de la parte que en la imagen mira al objeto a la parte que ella tiene de subjetiva, de sentimental, de porciúncula de un yo» (EEP 678). Desrealizar o desvivir el ciprés es quedarse con lo que es como sentimiento o lugar sentimental, como cosa del yo, la conciencia de el ciprés. En esa región de la conciencia de, es decir, «el lugar sentimental o la forma yo» (EEP 677) de las cosas, ahí es donde se localiza el arte. En definitiva, Ortega denomina deshumanización a realizar la epoché, suspender el vivir, y reducirse a los eidos de la conciencia de, a lo que nos son las cosas como presencias inmediatas ante la conciencia. A este ámbito intrasubjetivo se refiere Ortega cuando afirma que con la «operación de deshumanizar (...) no se trata de pintar algo que sea por completo distinto de un hombre, o casa, o montaña, sino de pintar un hombre que se parezca lo menos posible a un hombre» (DA 859), o sea, la idea o conciencia de hombre, lo que nos es la realidad hombre en tanto presencia inmediata ante la conciencia. Este es el objeto con el que trabaja el arte, con el «hombre» desrealizado o desvivido, el hombre que se parece lo menos posible a un hombre. Tiene que parecerse lo menos posible a un hombre pero, al tiempo, sin dejar de ser hombre. Para Ortega el objeto que cumple esta paradójica condición de, sin ser totalmente diferente de la cosa real hombre, parecerse lo menos posible a ella es la conciencia de hombre, el molde mental hombre (EEP 675), la cápsula intrasubjetiva con la que nos referimos a la realidad «hombre», esto es, la intención significativa o mención «hombre», en la cual, del hombre, sólo hay nuestro mentarlo, intentarlo o referirnos a él. Este hombre desrealizado, reducido a su huella mental, concepto o intención, es el hombre que se parece lo menos posible a un hombre.

La tesis implícita que presenta Ortega en el Ensayo es que el arte siempre ha practicado de forma espontánea, irreflexivamente, la reducción y, por tanto, su presupuesto, la epoché, porque sólo así puede acceder a los lugares sentimentales de las cosas. Por tanto, el arte trabajaría ya de entrada, naturalmente, con las conciencia de que obtiene mediante esa operación no discursiva, o sea, con los moldes mentales o cápsulas intrasubjetivas mediante las que nos referimos a lo real. El arte desrealiza sin darse cuenta, deshumaniza sin enunciarlo; esto es, detiene las vivencias de la conciencia natural (vida) para reducirse espontáneamente a lo vivido intrasubjetivo, al plano de la objetividad primaria de nuestra conciencia de. Entonces, el artista reflexiona fenomenológicamente de forma natural, recuperando la conciencia de que queda desapercibida en el cogito lebendig. Sería una suerte de reflexión irreflexiva que le proporcionaría inmediatamente como material de trabajo las objetividades primarias, lo que todo nos es como presencia inmediata ante la conciencia. En este sentido, el arte siempre ha sido deshumanización. Esta comprensión del arte como epoché y reducción espontáneas aparece en Husserl y luego insiste en ella Gadamer. 
Basándose en declaraciones de Husserl en sus clases, un informe de Becker sostiene que Husserl pensaba que la reducción eidética —y, por tanto, también la epoché o suspensión del ejecutarse de toda posición de realidad como condición suya- se cumple espontáneamente (spontan erfüllt) en el arte ${ }^{30}$. Parece como si el arte fuera una especie de "fenomenología práctica o espontanea» frente a la fenomenología teórica que representa la filosofía ${ }^{31}$.

\subsection{La novedosa objetividad metafórica del arte como idea estética}

Ahora bien, la obra de arte no es una conciencia de o lugar sentimental: «Los sentimientos no son el término del trabajo poético» (EEP 677). La obra de arte realmente es una objetividad: «El objeto estético es literalmente un objeto, aquel que llamábamos ciprés sentimental» (EEP 677). Además es una nueva objetividad; concretamente «el ciprés-llama (...) es un nuevo objeto (...) el ciprés a quien, sin absurdo, podemos tratar como a una llama» (EEP 675). Los lugares sentimentales o conciencia de son los elementos con que trabaja el arte para crear a partir de ellos la novedosa objetividad metafórica e irreal que es toda obra de arte. Por eso advierte Ortega que «el sentimiento es en el arte también signo, medio expresivo, no lo expresado» (EEP 677). El ciprés/llama metafórico ha sido creado p. e. a partir de la identificación de las conciencia de el ciprés y la llama. Sólo en este plano de idealidad intrasubjetiva se pueden crear verdaderamente novedades - metáforas, obras de arte- que trascienden la realidad. De ahí que Ortega escriba que «la metáfora es la potencia más fértil que el hombre posee», y ello porque «todas las demás potencias nos mantienen inscritos dentro de lo real, de lo que ya es. Lo más que podemos hacer es sumar o restar unas cosas de otras. Sólo la metáfora nos facilita la evasión [de lo real] y crea entre las cosas reales arrecifes imaginarios» (DA 865). Las obras de arte por tanto no son ni realidades ni productos meramente subjetivos, sino objetividades estéticas. Así, subraya Ortega, «Don Quijote no es ni un sentimiento mío ni una persona real o imagen de una persona real: es un nuevo objeto que vive en el ámbito del mundo estético» (EEP 677), un mundo metafórico y virtual, distinto del mundo físico y del psicológico, ambos mundos reales. El «ciprés sentimental», el ciprés que es (irrealmente) llama, aquel hombre pintado que se parece lo menos posible a un hombre, no son sino estas objetividades metafóricas creadas a partir de las conciencia de respectivas obtenidas mediante desrealización de las realidades ciprés, llama o ser humano.

30 BeCKER, O., «Gelegentlichen Äußerungen E. Husserls in Vorlesungen u. dgl.», Von der Hinfälligkeit des Schönen und der Abenteuerlichkeit des Künstlers (1929). In: Festschrift E. Husserl zum 70. Geburtstag gewidmet, Tübingen, Niemeyer, 1974, pp. 27-52. Apud Gadamer, H-G., "Philosophie und Literatur» (1981), Ästhetik und Poetik I. Kunst als Aussage, Gesammelte Werke, Band 8, Tübingen, J. C. B. Mohr (Paul Siebeck), 1993, p. 255; «Philosophie und Poesie» (1977), GW, Bd. 8, p. 234.

31 Cfr. Richir, M., «Commentaire de Phénoménologie de la conscience esthétique», Revue d'esthétique 36 (1999), p. 22, 15-23. 
Elaborar el objeto estético a partir de las conciencia de tiene como consecuencia que toda obra de arte piensa, no conceptualmente desde luego. El arte piensa no discursivamente porque está hecho a partir de lo que nos son las cosas inmediatamente ante nuestra conciencia, es decir, a partir de lo que pensamos (sin conceptos) primariamente de ellas. La obra de arte como metáfora fundada sobre los pensamientos primarios que representan nuestras conciencia de no puede ser, a su vez, sino un pensamiento. El nuevo objeto creado a partir de esas objetividades primarias que no son sino los eidos originarios de las cosas, arroja algo de lucidez sobre la realidad, puesto que esas objetividades no son sino los moldes mentales - con el saber antepredicativo que incluyenen que se nos dan primariamente las cosas reales en nuestra vida. Con esas ideas primarias o moldes mentales, cada nueva objetividad metafórica, o sea, cada nueva obra de arte, crea un pensamiento novedoso, una idea estética. Teniendo en cuenta la espontaneidad que caracteriza a la reducción eidética del arte hacia esas objetividades, podría decirse, parafraseando a Heidegger ${ }^{32}$, que en la obra de arte acontece de forma espontánea el ponerse en obra la verdad del ente, mientras que en la filosofía sería resultado del juicio reflexivo predicativo. En el objeto estético se produce una reflexión natural sobre la verdad de lo existente. Por otra parte, desde esta perspectiva se llega a la misma conclusión que obtenía Kant acerca del arte cuando sostenía que su esencia es la idea estética (ästhetische Idee), o sea «una representación de la imaginación que provoca constantemente a pensar sin que, sin embargo, le sea adecuado ningún pensamiento, o sea, ningún concepto, y que, por tanto, ningún lenguaje puede ni expresar ni comprender del todo ${ }^{33}$. También en esta estética orteguiana la metáfora que es la obra de arte es un nuevo objeto que, precisamente por estar elaborado a partir de los conceptos con que intencionamos primariamente los objetos, supera todas esas conciencia de de donde procede. El objeto estético excede por definición toda intención significativa, todo molde mental en que pretendamos atraparlo. En el sujeto, en lo intrasubjetivo, se produce un objeto que rebasa los poderes del propio sujeto.

\subsection{El empirismo lógico de la estética}

Ortega considera que llamamos «realidad» a lo previsto, a lo que sabemos cómo va a ser, es decir, a lo normal, al hecho de que las cosas obedezcan su norma, su regla habitual de conducta: «Es real, escribe, no tanto lo visto como lo previsto; no tanto lo que vemos como lo que sabemos» (MQ, 807). Por eso realidad es lo previsible, aquello de lo que no esperamos sorpresas, de modo que sólo es posible en ella lo predecible según leyes. En el universo de lo real no cabe la aventura, que representa para Ortega «lo imprevisto, lo impensado, lo nuevo», lo que «quiebra como un cristal la opresora, insistente realidad» (MQ,

32 Cfr. Heidegger, M., Der Ursprung des Kunstwerkes, pp. 21s, 25, 49, 59.

33 Kant, I., Kritik der Urteilskraft, Werkausgabe, her. v. W, Weischedel, Band X, Frankfurt a. M., Suhrkampk, 1977, § 49, pp. 249s. 
807). Desde esta perspectiva, verdaderamente novedoso sólo puede ser lo imprevisto, lo que rompe la conocida legalidad que determina la realidad. Estos objetos estéticos y metafóricos son novedades que quiebran esas leyes de lo real y, por ello, trascienden la realidad. La metáfora es potencia verdaderamente creativa porque sus productos, las obras de arte, están al margen de esas leyes que rigen lo real y según las cuales un ciprés no es —ni puede ser- una llama ni una mejilla una rosa. Ahora bien, estas leyes no rigen para el mundo donde se mueve el arte, la región intrasubjetiva de los lugares sentimentales o forma/ yo de las cosas donde sí que puede identificarse la conciencia de un ciprés con la de una llama y el molde mental de mejilla con el de rosa. Ese orbe ideal de la conciencia de está al margen de la legalidad que estructura la normalidad de lo real y, por eso, los objetos producidos con materiales obtenidos de ese universo desafían las leyes de la realidad y se sitúan sorprendentemente fuera de la normalidad: «El sentimiento-ciprés y el sentimiento-llama son idénticos. ¿Por qué? ¡Ah!, no sabemos por qué; es el hecho siempre irracional del arte, es el absoluto empirismo de la poesía» (EEP 676). Por tanto, la irracionalidad que caracteriza a este ámbito significa que en él, a diferencia de lo que ocurre en el orbe real, no impera ninguna legalidad conocida a priori, una lógica de la previsión. Las leyes rigen a priori la realidad y además nos son conocidas, razón por la cual podemos prever lo real. En el universo estético no hay previsión, hay ignorancia previa e irracionalidad, y por eso no hay apriorismo sino empirismo. No se hacen obras de arte siguiendo leyes conocidas; no se puede prever una obra de arte. De ser así el mundo del arte sería el patrimonio de la normalidad, cuando, más bien, es el imperio de la anormalidad.

Pero nada de esto significa que el mundo artístico sea absolutamente caótico e irracional. La irracionalidad a la que se refiere Ortega respecto de lo estético es relativa a la inexistencia de leyes a priori que determinan absolutamente la constitución del objeto artístico, pero no es absoluta. El ámbito estético también tiene leyes, pero no son leyes a priori conocidas. Cuando Ortega subraya que no sabemos por qué el sentimiento-ciprés y el sentimiento-llama son idénticos quiere decir que no poseemos ninguna ley previa que determine la creación de una identidad de esa índole, y sólo en este sentido es irracional dicha fusión. Pero, añade, es un hecho, ahí está el objeto artístico y metafórico ciprés/llama que nos descubre esa identidad formal entre aquellos objetos o moldes mentales. Tal es el empirismo estético. Las leyes que rigen en el mundo del arte son a posteriori, se trata de una lógica empírica, porque son las obras las que crean y nos dan a conocer o descubren las leyes, y no al revés, las leyes las que determinan las obras: "Cada metáfora es el descubrimiento de una ley del universo. Y, aun después de creada una metáfora, seguimos ignorando su por qué. Sentimos, simplemente, una identidad, vivimos ejecutivamente el ser ciprés-llama» (EEP 677). Cada creador descubre esas leyes y cada obra de arte es la revelación de algunas de las normas intrínsecas de ese mundo, las cuales sólo mediante las propias obras vamos conociendo. El empirismo artístico implica que no existe $a$ priori el mundo de lo estético como un objeto independiente que las obras concretas representan, sino que son los artistas con sus obras los que 
lo van creando: «El yo de cada poeta es un nuevo diccionario, un nuevo idioma al través del cual llegan a nosotros objetos, como el ciprés-llama, de quien no teníamos noticia» (EEP 679). Afirmar, como suele hacerse, que cada artista tiene su particular estilo equivale entonces en Ortega a sostener que cada artista posee su propia manera de irrealizar, esto es, de situarse ante las conciencia de y, mediante las identidades que descubre entre ellas, crear esas nuevas, sorprendentes y anormales objetividades que son las obras de arte: «La peculiar manera que en cada poeta hay de desrealizar las cosas es el estilo» (EEP 678).

\subsection{El arte de vanguardia como epoché y reducción intencionales}

$\mathrm{El}$ arte siempre ha deshumanizado. La peculiaridad del arte de vanguardia según Ortega es que realiza la epoché y la reducción eidética que constituyen esencialmente al arte de manera consciente. El arte vanguardista entonces se sitúa deliberadamente en los moldes mentales de la conciencia de, algo en lo que no por casualidad coincide epocalmente con la fenomenología de Husserl y así lo subraya Ortega. En Sobre el punto de vista en las artes de 1924 Ortega reconoce un paralelismo en la evolución histórica de la filosofía y la pintura occidentales que las ha llevado de centrarse en las cosas (realidad externa) a basarse en ese ámbito de las ideas, o sea, en las conciencia de (lo intrasubjetivo), pasando por el estadio intermedio de atender a las sensaciones (lo subjetivo) (PVA 171). El final de esta evolución se ha consumado en la fenomenología husserliana y el arte de las vanguardias, que para Ortega, en este sentido, son afines cultural e intelectualmente. Aunque ya antes de la vanguardia Cézanne anticipó este movimiento de internación o intrasubjetivización: «Desde él, escribe Ortega, la pintura sólo pinta ideas - las cuales, ciertamente, son también objetos, pero objetos ideales, inmanentes al sujeto o intrasubjetivos» (PVA 171). En La deshumanización del arte confirma que ese movimiento o dirección radical se realiza por fin en la vanguardia: «El expresionismo, el cubismo, etc., han sido en varia medida intentos de verificar esta resolución en la dirección radical del arte. De pintar las cosas se ha pasado a pintar las ideas: el artista se ha cegado para el mundo exterior y ha vuelto la pupila hacia los paisajes internos y subjetivos» (DA 868). El arte de vanguardia que corre históricamente en paralelo a la fenomenología ha hecho de la idea intrasubjetiva su objeto y trata no ya cosas reales, sino esas cosas desrealizadas, deformadas, reducidas a su idea o conciencia de. Desde esta perspectiva hay que interpretar el tercer capítulo de La deshumanización, titulado no por casualidad Unas gotas de fenomenología, en el que Ortega expone la epoché y la reducción como elementos constitutivos de su estética fenomenológica. En este capítulo presenta la relación cada vez más distante de varios puntos de vista con la realidad natural, vivida o humana, en concreto con la agonía de un hombre ilustre: desde la mujer del moribundo que vive esa agonía como tal realidad, sin distancia, sin ningún tipo de desconexiones ni suspensiones para hallar sólo realidad vivida, hasta el pintor, que la desconecta radicalmente para verla como puro espectáculo, como sentido (estético), como realidad contemplada, lo que supone máxima distancia (DA 
855). Lo que ha cambiado de la mujer al artista es la actitud, pasando de vivir a contemplar, pero esta suspensión del vivir es lo que permite que la vida se nos presente como objeto, de modo que para desrealizar la realidad vivida hay que desconectarla, efectuar la epoché: «Para que podamos ver algo, para que un hecho se convierta en objeto que contemplamos, es menester separarlo de nosotros y que deje de formar parte viva de nuestro ser» (DA 855). El artista ha desrealizado y lo que ve es aquella realidad vivida reducida ya a conciencia de estética o artística. Se ha vuelto de espaldas a la realidad natural para volverse sobre lo concienciado. Desrealizar implica, en primer lugar, practicar la epoché: desconectar la realidad vivida o natural de las cosas para quedarnos con esa misma cosa en tanto irrealizada, es decir, como realidad contemplada. Por tanto, en segundo lugar, supone la reducción eidética: liberar a lo vivido de su realidad para reducirlo a su idealidad intrasubjetiva o conciencia de. El arte deshumanizado en suma es el que se reduce a lo concienciado, la idea, a nuestra conciencia de o lugar sentimental de las cosas.

Dado que, según Ortega, no se puede aprehender la cosa real misma, porque ésta necesariamente se nos da en una idea, conciencia de o intención significativa, y «entre la idea y la cosa hay siempre una absoluta distancia» (DA 867), entonces el arte realista dogmático estaba condenado al fracaso, porque no podía representar lo que pretendía, la realidad misma. Ese arte acababa siendo idealista ingenuo, ya que finalmente representaba - sin saberlo- una idea a la que tomaba realidad. Lo que ha cambiado en el arte de vanguardia es que el artista ya es consciente de que ve la realidad a través de ideas y de que aquélla excede a éstas. Por tanto, lo que hace es practicar intencionalmente la epoché, detener la inclinación natural del vivir consciente a creer que lo que piensa (la idea) es la realidad y, «en vez de dejarnos ir en esta dirección del propósito, lo invertimos y, volviéndonos de espaldas a la presunta realidad, tomamos las ideas según son -meros esquemas subjetivos» (DA 868). Al suspender aquella tendencia natural que lleva a confundir realidad e idea, y tomar conciencia deliberadamente de la conciencia de, el arte vanguardista y la filosofía fenomenológica separan - distinguen - idea y cosa. El artista de la vanguardia practica conscientemente la epoché para reducirse, como el fenomenólogo, a la idea (conciencia de) de las cosas. Antes pintaba ideas inconscientemente creyendo pintar las cosas reales y ahora pinta intencionalmente la idea: «De pintar las cosas se ha pasado a pintar las ideas» (DA 868). Este es, pues, el uso inesperado que el arte nuevo hace de esta inversión inhumana. El artista de vanguardia ya no hace arte en actitud natural, sino en actitud reflexiva o fenomenológica. El arte siempre es epoché y reducción, trabajo con la conciencia de, pero ahora, en la vanguardia, practica esta reflexión expresamente. Considerar entonces, como hace Ortega, que el arte de vanguardia es un arte deshumanizado equivale a considerarlo como un arte fenomenológico en tanto que ejecuta la epoché y se reduce a la conciencia de, convertida ya de forma consciente en el nuevo objeto artístico. Al limitarse a la conciencia de, el arte de vanguardia es más verdadero que el arte realista. En efecto, «el pintor tradicional que hace un retrato pretende haberse apoderado de la realidad de la persona» (DA 868), de la cosa, que 
era su supuesto objeto, cuando realmente lo que ha pintado ha sido su idea o conciencia de la persona. En cambio, el artista de vanguardia, en vez de querer pintar la persona misma, como pretendía ingenua e inútilmente el pintor tradicional, quiere conscientemente pintar su propia idea de ella: «Entonces, concluye Ortega, el cuadro sería la verdad misma» (DA 868).

Universidad de Sevilla

Antonio Gutiérrez Pozo

Depto. de Estética e Historia de la Filosofía

agpozo@us.es

[Artículo aprobado para publicación en diciembre de 2016] 